\title{
Effects of acid deposition on the avoidance behavior of Folsomia candida (Collembola, Isotomidae)
}

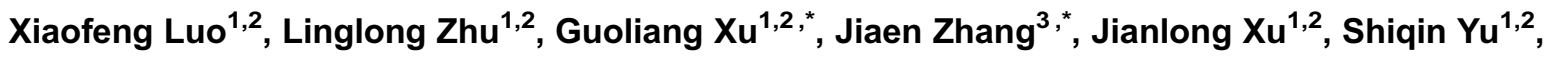 \\ Xiaohua Chen ${ }^{1,2}$
}

1 School of Geographical Science and Remote Sensing, Guangzhou University, Guangzhou 510006, China

2 Guangdong Province Rural Water Environment Non-point Source Pollution Comprehensive Treatment Engineering Technology Research

Center, Guangzhou 510006, China

3 Guangdong Provincial Key Laboratory of Eco-circular Agriculture, South China Agricultural University, Guangzhou 510642, China

\section{H I G H L I G H T S}

- This study clarified the direct responses of soil fauna to acid deposition.

- Soil fauna showed a certain adaptability to the changing $\mathrm{pH}$ of acid deposition.

- There was interaction between $\mathrm{pH}$ and exposure duration on the avoidance behaviors.

- Folsomia candida showed signifcant avoidance behavior at $\mathrm{pH}<4.5$.

\section{ARTICLE INFO}

Article history:

Received August 29, 2020

Revised April 7, 2021

Accepted April 29, 2021

Keywords:

Collembolan

Acid rain

Behavioral avoidance
GRAPHICAL ABSTRACT

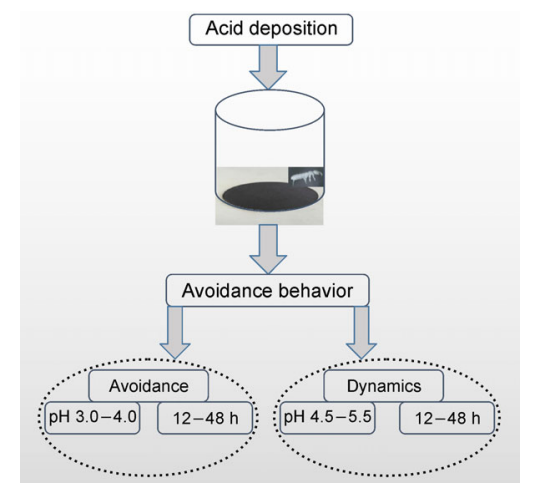

A B S T R A C T

Excessive acid deposition causes soil acidification, and changes the soil microhabitat, thus affecting the survival and reproduction of soil organisms. Folsomia candida (Collembola, Isotomidae), as a model organism, is widely used to assess the chemical toxicity in soil, and its avoidance response can indicate the environmental changes. In this study, we used Folsomia candida to assess the risks of acid deposition on soil ecosystems. Different $\mathrm{pH}$ (3.0, 3.5, 4.0, 4.5, 5.0, and 5.5) treatments were set up in petri dish experiments, and the avoidance behavior of Folsomia candida was measured after 12,24 , and $48 \mathrm{~h}$ exposure to the $\mathrm{pH}$ conditions. The results indicated that (1) both the exposure duration and $\mathrm{pH}$ level influenced avoidance behavior of collembolan. (2) After $12 \mathrm{~h}$ exposure, most of the individuals showed avoidance behavior but without significant differences among the treatments. (3) After $24 \mathrm{~h}$ exposure, significant avoidance behavior was observed at $\mathrm{pH} 3.0,3.5$, and 4.0. (4) After $48 \mathrm{~h}$ exposure, avoidance behavior was found in all treatment conditions except for $\mathrm{pH} 5.5$. This study clarified the direct responses of soil fauna to acid deposition, and indicated that both $\mathrm{pH}$ and length of exposure influenced the avoidance behavior of Folsomia candida. During the experimental period, the collembolan reacted negatively and showed consistent avoidance behavior at $\mathrm{pH} 3.0,3.5$, and 4.0. Reversed avoidance behavior was apparent between $\mathrm{pH} 4.5$ and 5.0 and not observed at $\mathrm{pH} 5.5$, indicating that the latter was the preferred $\mathrm{pH}$ environment.

(c) Higher Education Press 2021

\section{Introduction}

\footnotetext{
* Corresponding authors

E-mail address: xugl@gzhu.edu.cn (G.L. Xu); jeanzh@scau.edu.cn (J.E. Zhang)
}

In the past decades, the release of $\mathrm{SO}_{2}$ and $\mathrm{NO}_{x}$ from fossil fuel combustion has led to a $20 \%-70 \%$ increase in atmo- 
spheric acid deposition compared to that before the industrial revolution (Lu et al., 2014). With continuing economical and industrial development, acid deposition is predicted to increase dramatically in the coming decades. The proportion of nitric acid deposition is also continually rising (Mei et al., 2010). Excessive nitrogen deposition in the environment adversely affects the natural balance, resulting in detrimental effects on both organisms (Zhang, 2010; Li et al., 2019) and ecosystems (Xie et al., 2010; Qiu et al., 2013; Chen et al., 2015). However, nitrogen is also an essential element in living organisms, and the complex effects of nitrogen deposition on organisms may occur depending on both the nitrogen amount and its chemical form (Qiu et al., 2013; Cheng et al., 2017). Although there is a growing consensus on the effects of nitrogen deposition on water bodies (Xu et al., 2016; Liu et al., 2018) and plants (Huang et al., 2007; Li et al., 2015; Mao et al., 2018; Qu et al., 2019), the effects on soil animals are poorly understood (Ayu et al., 2013; Nijssen et al., 2017).

Soil fauna act as the good indicator of environmental change. When habitats change, producing stress and environmental pressure, the soil fauna can escape and move to more suitable habitats; this is described as avoidance behavior (Cecília et al., 2013). The avoidance reaction of terrestrial invertebrates is frequently used as an index of soil quality (ISO, 2011). The springtail Folsomia candida (Collembola, Isotomidae) is widely distributed with large populations (Lin et al., 2019; Bellinger et al., 2020), which plays an important role in soil ecosystems (Fountain and Hopkin, 2005), and is responsive to small changes in the environment (Chen et al., 2007; Xu et al., 2007; Sun et al., 2014). In addition, F. candida is easily bred in the laboratory (Fountain and Hopkin, 2005; Lin et al., 2019), making it an ideal organism to assess soil quality and environmental pollution (Chen et al., 2007), and it has become the standard model organism in ecotoxicology (Fountain and Hopkin, 2005). However, the application of Folsomia candida in ecotoxicology has mostly concentrated on the effects of pesticides (Talyta et al., 2018; Tiago et al., 2019; Fernanda et al., 2019) and heavy metals (Andressa et al., 2016; Zhang et al., 2019; Lin et al., 2019), while it has seldom been used as an indicator of the effect of acid deposition.

Krogh (1995) suggested that springtails could migrate by "perceiving" the presence of soil pollutants, and Heupel (2002) believed that avoidance behavior of springtails could be used as an early indicator of soil pollution. In this study, F. candida was used as the indicator organism with a filter paper contact method for mimicking acid deposition, to investigate the effects of acid deposition on the avoidance behavior of F. candida.

\section{Materials and methods}

\subsection{Acid solutions preparation}

According to the chemical composition of acid rain in China
(Zhang, 2004), we used sulfuric acid and nitric acid to prepare a solution with the molar ratio of $\mathrm{SO}_{4}{ }^{2-}: \mathrm{NO}_{3}{ }^{-}=2: 1$. The $\mathrm{pH}$ values of the solution was diluted to $\mathrm{pH}=3.0,3.5,4.0,4.5,5.0$ and 5.5 , respectively, by adding deionized water. The $\mathrm{pH}$ values of these solutions were adjusted with a $\mathrm{pH}$ meter. To this end, these diluted acid solutions were stored at $4^{\circ} \mathrm{C}$.

\subsection{Collembola cultures and synchronizing}

F. candida cultures were maintained in laboratory on a moist substrate of plaster of paris and activated charcoal (8:1 ratio), at $20 \pm 1^{\circ} \mathrm{C}$, under a photoperiod of $16: 8$ (light:dark). The organisms were fed twice a week with dried yeast (Angel Yeast CO., LTD). Synchronized cultures were established for the experiments, stimulating egg laying by transferring adults into new breeding substrate. After $48 \mathrm{~h}$, the eggs were laid and the adults removed. The eggs hatched after approximately 12 days, and 10-12 days juveniles were used for the avoidance test. All tests were conducted in the same laboratory under similar climatic conditions.

\subsection{Avoidance test}

The avoidance test was conducted based on the guideline ISO 17512-2 (2011). At the beginning of the experiment, a piece of quantitative filter paper was cut into two pieces with equal size ( $A$ and $B$ ). The filter paper $A$ was soaked into deionized water, and held in the air by tweezers until drips stopped, and slowly moved into a culture dish. The filter paper $B$ was soaked in an acid solution, and placed in the same culture dish in the same way. There is an interval of about $1 \mathrm{~mm}$ between the filter papers to avoid any contaction. After that, 20 collembola (Folsomia candida) synchronized to 12$14 \mathrm{~d}$ were placed in the interval. The collembola were cultured at $18 \pm 2^{\circ} \mathrm{C}$ under a photoperiod of $16: 8$ (light:dark). At $12 \mathrm{~h}$, $24 \mathrm{~h}$, and $48 \mathrm{~h}$, collembolan individual were counted on filter paper $A$ and $B$ in each culture dish, respectively. We repeated each $\mathrm{pH}$ treatment by 18 times. However, at $12 \mathrm{~h}$, we counted the number of collembola only in 10 dishes.

Avoidance response (A) was calculated as follows:

$$
\mathrm{A}=(\mathrm{C}-\mathrm{T}) / \mathrm{N} \times 100
$$

where $C$ is the number of collembolans observed in the filter paper $A ; T$ is the number of collembolans observed in the filter paper $\mathrm{B}$; $\mathrm{N}$ is the total number of collembola per replicate. The tests would be invalid if the number of dead or/and missing were larger than 20\% per treatment (Cecília et al., 2013).

\subsection{Data analysis}

All data were examined for both normality and homogeneity of variance (Kolmogorov-Smirnov test). Log-transformation was applied to obtain normal distribution of the data. LSD test was used to further determine differences among different means at the $95 \%$ confidence level. Two way analysis of variance 
(ANOVA) was performed to assess effects of $\mathrm{pH}$ and experimental duration of acid deposition on the avoidance responses of Folsomia candida. Statistical analyses were conducted using Microsoft Excel and IBM SPSS Statistics 25 software.

\section{Results}

\subsection{Effects of $\mathrm{pH}$ and experimental duration}

Two-way ANOVA was used to determine the effects and interactions of $\mathrm{pH}$ and duration of exposure on the avoidance responses of $F$. candida. The results showed that the $\mathrm{pH}$ levels and experimental duration, separately and together, had significant effects on the avoidance responses of $F$. candida $(P<0.05$, Table 1$)$.

\subsection{Effects of $\mathrm{pH}$ levels on springtail behavior}

Springtails in all $\mathrm{pH}$ treatments, except for $\mathrm{pH} 5.5$, exhibited avoidance responses in the first $12 \mathrm{~h}$. However, there were no significant differences among the treatments (Fig. 1A). After $24 \mathrm{~h}$, avoidance responses were only observed at $\mathrm{pH} 3.0-4.0$ with apparent non-avoidance responses at $\mathrm{pH}$ 4.5-5.5 (Fig. 1B).

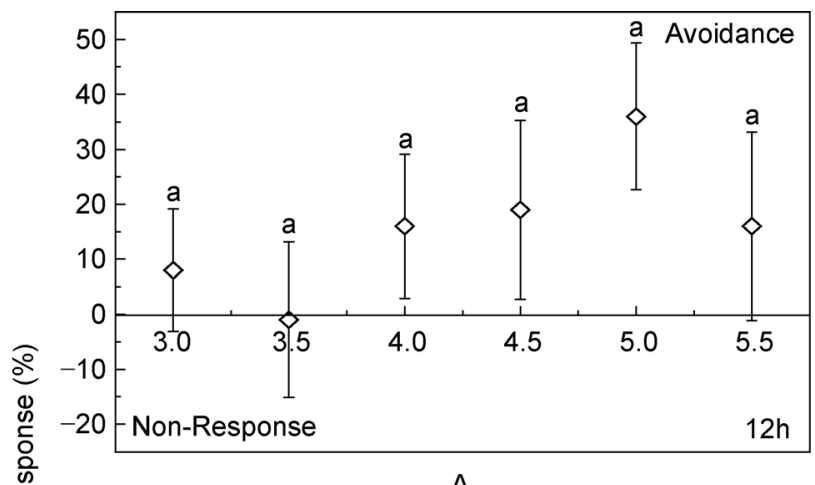

A

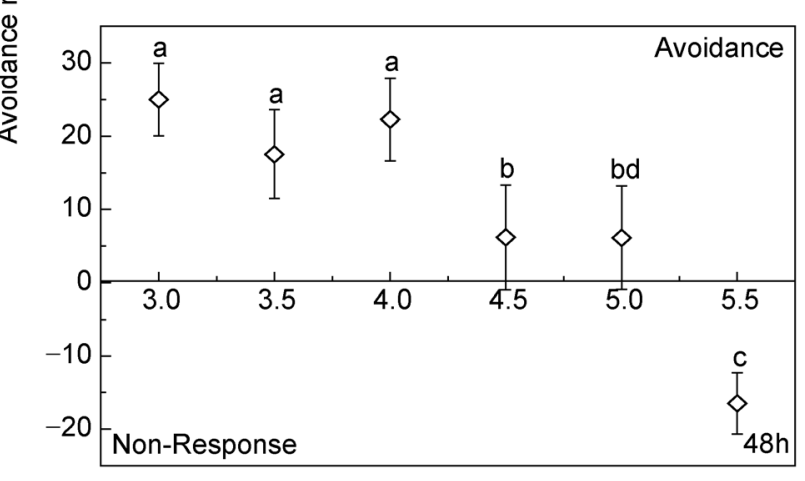

C
Table 1 Effects of $\mathrm{pH}$ and experimental duration of acid deposition on the avoidance responses of Folsomia candida

\begin{tabular}{lcccc}
\hline & df & MS & $F$ & $P$ \\
\hline Duration & 2 & 3894.063 & 4.194 & 0.016 \\
$\mathrm{pH}$ & 5 & 5718.057 & 6.158 & 0.00 \\
Duration ${ }^{*} \mathrm{pH}$ & 9 & 3824.452 & 4.119 & 0.00 \\
\hline
\end{tabular}

Significant changes in the springtail avoidance responses were observed after $48 \mathrm{~h}$ for most of the $\mathrm{pH}$ treatments, while the tendency responses were not observed in $\mathrm{pH} 5.5$ treatment. The avoidance responses in the $\mathrm{pH} 3.0-4.0$ were significantly higher than those in the $\mathrm{pH} 4.5-5.0$ range $(P<0.05$, Fig. 1C).

3.3 Dynamics of springtail behavior during the experimental period

During the experimental period, springtails reacted negatively and showed consistent avoidance behaviors in the $\mathrm{pH} 3.0$, 3.5 , and 4.0 treatments. This behavior showed reversal between $\mathrm{pH}$ 4.5-5.0, and at $\mathrm{pH} 5.5$, the collembolan individuals did not show avoidance behavior (Fig. 2)

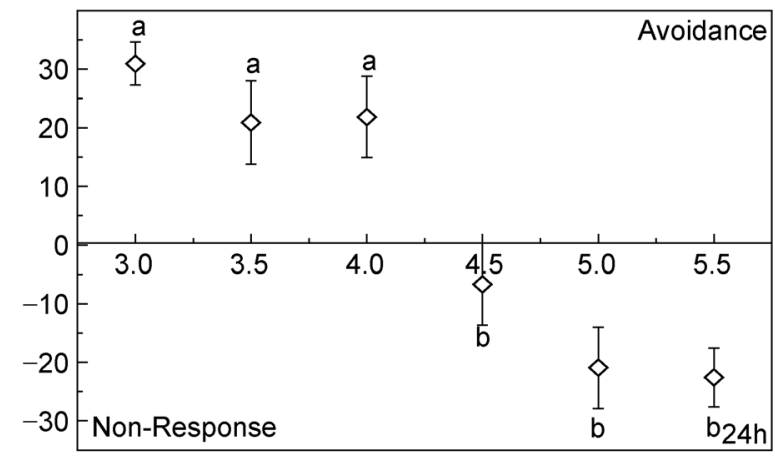

B

$\mathrm{pH}$

Fig. 1 Avoidance responses of springtails under to different $\mathrm{pH}$ levels of acid deposition. Avoidance responses are expressed as mean values \pm standard error. 


\section{Discussion}

\subsection{Effects of acid deposition on springtail behavior}

Chapman et al. (2013) and Jänsch et al. (2005) found that the springtail $F$. candida is adaptable to a wide range of $\mathrm{pH}$ environments, for example, $\mathrm{pH} 3.2-7.7$, even reaching $\mathrm{pH} 3.0$ or lower, but with the optimal $\mathrm{pH}$ being 6.0. Rusek and Marshall (2000) reported that egg production is the highest between $\mathrm{pH}$ 5-7 but still occurs at $\mathrm{pH} 3.3$ although with only $10 \%$ of the normal rate. Greenslade and Vaughan (2003) reported that soils with $\mathrm{pH}$ 5.4-6.6 were optimal for the egg production of $F$. candida. In artificial soils, Sandifer and Hopkin (1996) found an overall decrease in the reproduction of $F$. candida at $\mathrm{pH} 5.0$ and 4.5 compared to $\mathrm{pH} 6.0$. In the avoidance tests with $F$. candida performed in our study, overall, we observed an avoidance response at acid levels with $\mathrm{pH}$ between 3.0-4.0, with no avoidance response occurring between $\mathrm{pH} 4.5-5.5$; no mortality was observed at any of the treatment levels. The different results above may be attributed to differences in the test substrate, the time of exposure to the acid environment, and the evaluation index. Generally, studies describing avoidance responses in F. candida have used different soils (Andressa et al., 2016;
Fernanda et al., 2019). However different natural soils varied with the acidity and the potential buffering capacity, which may reduce the $\mathrm{pH}$ change. In this study, a direct contact method was used which avoided the potential complications of acid buffering in natural soil as well as the influence of acidity on soil properties, both of which could influence the behavior of springtails (Amorim et al., 2005), especially short-term behavioral changes under acid deposition. The tolerance range and the optimum $\mathrm{pH}$ for the springtail $F$. candida in an acidic environment influence their mortality, growth, and reproductive rates. In contrast to the springtails' short-term behavior, it was observed that the collembolans did not die or showed growth inhibition under acid conditions, indicating that they have strong environmental adaptability and tolerance of a wide range of acidity. The avoidance response is a short-term response to stress which may be the initial step in a process of long-term tolerance and optimal acidity monitoring. This indicates that the collembolan's approach and avoidance behavior is a sensitive response to changes in environmental acidity. The springtail $F$. candida is capable of survival over a relatively wide $\mathrm{pH}$ range (Chapman et al., 2013), demonstrating that it has strong environmental adaptability. While it is possible that there may be a precise acidity threshold beyond which the springtails' physiological and ecological behavior is irreversibly altered.
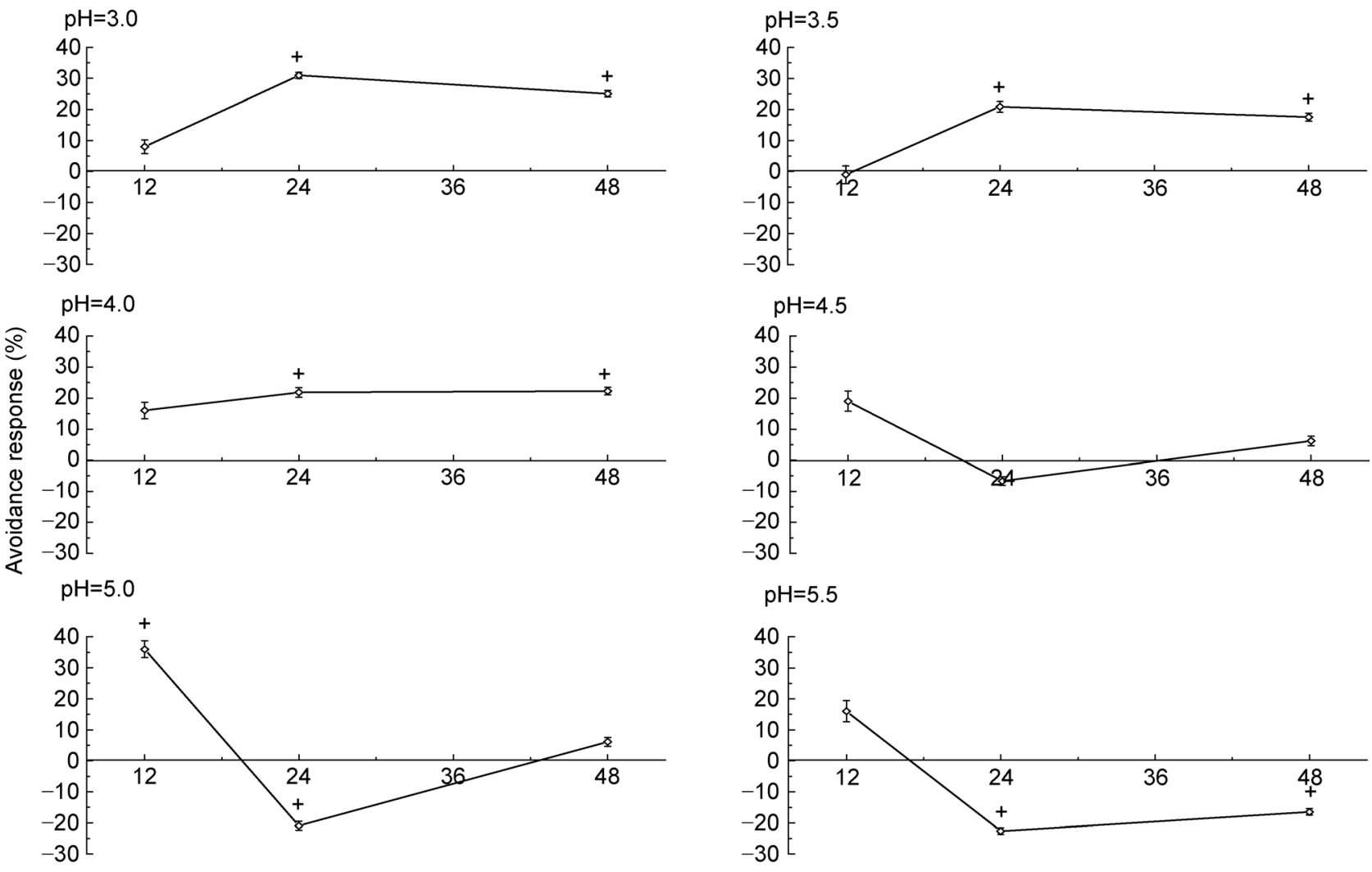

Time (h)

Fig. 2 Changes in springtail behavior with time under different $\mathrm{pH}$ conditions. 


\subsection{Dynamic avoidance behavior of springtails}

Ethological observations have indicated that $F$. candida prefers weakly acidic environments and that strongly acidic environments induce stress. The behavior of springtails has a clear time dynamic and reflects specific environmental stresses. In this study, it was found that over a 12-48 h period, the springtails showed the greatest avoidance reaction at $\mathrm{pH} 3.0-4.0$. At $12 \mathrm{~h}$, there was an initial avoidance response at $\mathrm{pH} 4.5-5.5$ (Fig. 1). From $24 \mathrm{~h}$ to $48 \mathrm{~h}$, the highest avoidance response occurred in strongly acidic environments with a stable non-avoidance response in the weakly acidic environment, indicating that both exposure time and acid treatment played important roles in the springtail behavior (Table 1). In the short term, strong acid deposition directly affected springtail behavior.

With the extension of the exposure time (12-48 h), the collembolan appeared to gradually acclimate to the acid condition. This suggests that the springtails underwent a process of transient adaptation with a gradually decreasing response amplitude, and then changes from a non-avoidance to an avoidance response (Fig. 2). Zhang (2004) found that, during a six months' incubation, soil faunas gradually adapted to the weak acid environment of $\mathrm{pH}$ values between 5.0 and 5.5 , and the community density went through four stages, namely, reduction, rebound, recovery, and stability. Finally, the abundance of the soil fauna community essentially returned to the level of the control treatment. Therefore, the degree and duration of acid deposition should be considered in evaluating the effect of acid deposition on the environment. A high degree of acid deposition can have a direct effect in a short time, while, on the other hand, a less intense deposition will result in chronic accumulation over a prolonged time. Boxman et al. (1998) found that high acid deposition could inhibit soil fauna while Magill et al. (2000) observed that moderate to low acid deposition could increase biodiversity. Thus, the shortterm behavioral response of the $F$. candida represents an important ecological advantage that allows an advanced detection of the change in environmental acidity. In the future monitoring and evaluation the effect of acid deposition, it is necessary to combine short-term acute toxicity testing and long-term chronic toxicity testing, direct and indirect effects, laboratory and field experiments, to maintain the consistency, integrity, and comprehensiveness of data, and provide a theoretical basis for the ecological risk assessment of acid deposition.

\section{Conclusion}

In this study, acid treatment acted as an independent factor inducing avoidance behaviors in soil fauna over a specific period. Although springtails are tolerant of a relatively wide $\mathrm{pH}$ range, their preference for different acidity differs significantly, showing an avoidance reaction to strongly acidic environments and a non-avoidance to weakly acidic conditions. In addition, the collembolan also showed clear stress behavioral responses to environmental changes in acidity. The results show that:

1) F. candida showed a significant avoidance response to environments below $\mathrm{pH} 4.0$ but did not show clear avoidance to environments at $\mathrm{pH}>4.0$.

2) The collembolan species $F$. candida has an obvious stress response to changes in environmental acidity.

\section{Acknowledgments}

This study was supported by the National Natural Science Foundation of China (42071061, U1701236).

\section{References}

Amorim, M.J., Rçmbke, J., Scheffczyk, A., Nogueira, A.J., Soares, A. M., 2005. Effect of different soil types on the Collembolans Folsomia candida and Hypogastrura assimilis using the herbicide phenmedipham. Archives of Environmental Contamination and Toxicology 49, 343-352.

Andressa, C.B., Júlia, C.N., Maria, E.F., Emmanoel, V.S., 2016. Ecotoxicity of mercury to Folsomia candida and Proisotoma minuta (Collembola: Isotomidae) in tropical soils: Baseline for ecological risk assessment. Ecotoxicology and Environmental Safety 127, 22-29.

Ayu, T., Jaroslav, H., Tomás, C., Jan, F., 2013. Soil fauna increase nitrogen loss in tilled soil with legume but reduce nitrogen loss in non-tilled soil without legume. Soil Biology \& Biochemistry 60 , 105-112.

Bellinger, P.F., Christiansen, K.A., Janssens, F., 2020. Checklist of the Collembola of the World. [EB/OL].[2020-03-27]. http://www. collembola.org.

Boxman, A.W., Blanck, K., Brandrud, T., Emmett, B.A., Gundersen, P., Hogervorst, R.F., Kjønaas, O.J., Persson, H., Timmermann, V., 1998. Vegetation and soil biotare sponse to experimentallychanged nitrogen inputs in coniferous forest ecosystems of the nitrex project. Forest Ecology and Management 101, 65-79.

Cecília, M.S., Sara, C.N., Amadeu, M.V., Mónica, J.B., 2013. Dimethoate affects cholinesterases in Folsomia candida and their locomotion-false negative results of an avoidance behaviour test. Science of the Total Environment 443, 821-827.

Chapman, E.E., Dave, G., Murimboh, J.D., 2013. A review of metal $(\mathrm{Pb}$ and $\mathrm{Zn}$ ) sensitive and $\mathrm{pH}$ tolerant bioassay organisms for risk screening of metal-contaminated acidic soils. Environmental Pollution 179, 326-342.

Chen, D.M., Lan, Z.C., Hu, S.J., Bai, Y.F., 2015. Effects of nitrogen enrichment on belowground communities in grassland: Relative role of soil nitrogen availability vs soil acidification. Soil Biology \& Biochemistry 89, 99-108.

Chen, J.X., Ma, Z.C., Yan, H.J., 2007. Roles of springtails in soil ecosystem. Biodiversity Science 15, 154-161.

Cheng, Z.L., Luo, Y., Zhang, T., Duan, L., 2017. Deposition of sulfur, nitrogen and mercury in two typical forest ecosystems in southern China. Environmental Sciences 12, 5004-5011. 
Donald, E.C., Alexander, N.G., Paul, G.F., 2010. The evolution and future of Earts nitrogen cycle. Science 330, 192-196.

Fernanda, B.S., Naiara, G., Monica, S.V., João, P.M., Cesar, A.M., Júlia, C.N., 2019. Laboratory and field tests for risk assessment of metsulfuron-methyl based herbicides for soil fauna. Chemosphere $222,645-655$.

Fountain, M.T., Hopkin, S.P., 2005. Folsomia candida (Collembolan): A"standard"soil arthropod. Annual Review of Entomology 50, 201 222.

Greenslade, P., Vaughan, G., 2003. A comparison of Collembola species for toxicity testing of Australian soils. Pedobiologia 47, 171-179.

Heupel, K., 2002. Avoidance response of different collembolan species to Betanal. European Journal of Soil Biology 38, 273-276.

Huang, Y.Z., Li, Z.X., Li, X.D., Yang, W.M., Li, H.F., Liu, D.L., Lu, B.S., 2007. Effects of acid deposition and atmospheric pollution on forest ecosystem biomass in southern China. Ecology \& Environment 16, 60-65.

Hutson, B.R., 1978. Influence of $\mathrm{pH}$, temperature and salinity on the fecundity and longevity of four species of Collembola. Pedobiologia 18, 163-179.

ISO, 2011. Soil quality-Avoidance Test for Determining the Quality of Soils and Effects of Chemicals on Behaviour-part 2: Test with Collembolans (Folsomia candida). No: 17512-2, International standardization Organization, Geneva.

Jänsch, S., Amorim, M., Rçmbke, J., 2005. Identification of the ecological requirements of important terrestrial ecotoxicological test species. Environmental Reviews 13, 51-83.

Krogh, P.H., 1995. Does a heterogeneous distribution of food or pesticide affect the outcome of toxicity tests with Collembola? Ecotoxicology and Environmental Safety 30, 158-163.

Li, H.S., Wang, J.S., Liu, X., Zhao, B., Zhang, C.Y., Zhao, X.H., 2015. Effect of simulation $\mathrm{N}$ deposition on herbaceous vegetation community in the plantation and natural forests of Pinus tabulaeformis in the Taiyue Mountain. Acta Ecologica Sinica 35, 3710-3721.

Li, X. Y., Luo, Y. M., Ke, X., S, M. M., 2011. Acute toxicity of copper pollution to Folsomia candida (collembolan) in soil. Acta Pedologica Sinice 1, 197-201.

Li, Z.Y., Qiu, X.R., Chen, G.T., Zheng, J., Li, J., Tu, L.H., 2019. Effects of long-term simulated nitrogen deposition on soil arthropods in a Pleioblastus amarus plantation in rainy area of western China. Chinese Journal of Ecology 38, 1419-1425.

Lin, X.L., Sun, Z.J., Ma, J., Zhao, L., Qin, X.P., Zhao, S.T., Yang, Q., Hou, H., 2017. Toxicity differences of different forms of antimony to soil-dwelling springtail (Folsomia candida). Ecotoxicology and Environmental Safety 36, 657-664.

Lin, X.L., Sun, Z.J., Zhao, L., Ma, J., Wu, Z.H., Zhou, C.Z., Li, X., Hou, $H ., 2019$. The toxicity of exogenous nickel to soil-dwelling springtail Folsomia candida in relation to soil properties and aging time. Ecotoxicology and Environmental Safety 174, 475-483.

Liu, L., Cai, M., Chen, F.Z., Yang, S.Y., Li, Y., 2018. Effects of simulated acid rain on $\mathrm{pH}$ in lakes with different trophic levels. Journal of Ecology and Rural Environment. 34, 917-923.

Lu, X., Mao, Q., Gilliam, F.S., Luo, Y., Mo, J., 2014. Nitrogen deposition contributes to soil acidification in tropical ecosystems. Global Change Biology 20, 3790-3801.

Magill, A.H., Aber, J.D., Berntson, G.M., McDowell, W.H., Nadelhoffer, K.J., Melillo, J.M., Steudler, P., 2000. Long-term nitrogen additions and nitrogen saturation in two temperate forests. Ecosystems (New York, N.Y.) 3, 238-253.

Mao, J.H., Xing, Y.J., Yan, G.Y., Wang, Q.G., 2018. A meta-analysis of the response of terrestrial plant biomass allocation to simulated $\mathrm{N}$ deposition. Acta Ecologica Sinica 38, 1-11.

Mei, X.Y., Yang, Y., Fang, J.D., 2010. Regime shift of acid rain type in area of Shanghai. Resources and Environment in The Yangtze Basin Resour Environ Yangtze Basin 19, 1075-1079.

Nijssen, M., Wallis, D., Siepel, H., 2017. Pathways for the effects of increased nitrogen deposition on fauna. Biological Conservation 212, 423-431.

Qiu, Q.Y., Chen, X.M., Liang, G.H., Zhou, G.Y., Zhang, D.Q., 2013. Effect of simulated acid deposition on chemistry of surface runoff in monsoon evergreen broadleaved forest in Dinghushan. Acta Ecologica Sinica 13, 4021-4030.

Qu, T.T., Yan, T., Zhang, W., Zeng, H., 2019. Responses of herbaceous community characteristics and biomass to nitrogen addition in a larix principis-rupprechtii plantation. Acta Scientiarum Naturalium Universitatis Pekinensis 55, 587-596.

Rusek, J., Marshall, V.G., 2000. Impacts of Airborne pollutants on soil fauna. Annual Review of Ecology and Systematics 31, 395-423.

Sandifer, R.D., Hopkin, S.P., 1996. Effects of pH on the toxicity of cadmium, copper, lead and zinc to Folsomia candida Willem (Collembola) in a standard test system. Chemosphere 1902, 2475-2486.

Spurgeon, D., Hopkin, S., 1995. Extrapolation of the laboratory-based OECD earthworm toxicity test to metal-contaminated fifield sites. Ecotoxicology (London, England) 4, 190-205.

Sun, Y., Lan, X.P., Shao, H.T., 2014. Advances of researches on soildwelling springtails as bioindicators. Chinese Agricultural Science Bulletin 30, 6-9.

Talyta, Z., Tamires, R., Suélen, S., José, P., Aleksandro, S., Dilmar, B., 2018. Ecotoxicological effect of fipronil and its metabolites on Folsomia candida in tropical soils. Environmental Toxicology and Pharmacology 62, 203-209.

Tiago, S., Sara, C., Tiago, N., Sara, L., João, R., Fernando, R., Ana, S. V., Andreia, F., Jorge, B., Dick, R., José, P.S., Nico, M., Marco, F.L., 2019. Fate and effects of two pesticide formulations in the invertebrate Folsomia candida using a natural agricultural soil. Science of the Total Environment 675, 90-97.

Xie, Y.X., Zhang, S.L., Feng, W., Zhao, X., Guo, T.C., 2010. Review of atmospheric nitrogen deposition research. Chinese Journal of Eco-Agriculture 18, 897-904.

Xu, F.D., Gao, Y., Dong, W.Y., Hao, Z., Xu, Y.J., 2016. Impact of atmospheric nitrogen and $\mathrm{pH}$ osphorus wet deposition on nitrogen and phosphorus export and associated water quality: a case study of forest watershed in the red soil area, Southern China. Acta Ecologica Sinica 36, 6409-6419.

Xu, J., Ke, X., Song, J., Luo, Y. M., 2007. Role of collembola in assessment of ecological risk of heavy metal contamination of soils. International Journal of Environmental Research and Public Health 44, 544-549. 
Zhang, L.L., Cornelis, A.M., Van, G., 2019. Effect of ageing and chemical form on the bioavailability and toxicity of $\mathrm{Pb}$ to the survival and reproduction of the soil invertebrate Enchytraeus crypticus. Science of the Total Environment 664, 975-983.

Zhang, M., 2010. Impact of acid deposition on the soil acidification and plant ecophysiological characteristics in Mt. Taishan. Shandong University Master's Thesis.

Zhang, P.J., 2004. Effect of simulated acid rain on soil fauna and karyotype analysis of acarina. Shandong Normal University Master's Thesis. 